\title{
A 40-year Retrospective Clinicopathological Study of Ameloblastoma in Iran
}

\author{
Nasrollah Saghravanian ${ }^{1}$, Jahanshah Salehinejad ${ }^{2}$, Narges Ghazi ${ }^{2 *}$, Mohammad \\ Shirdel $^{3}$, Mahsa Razi ${ }^{4}$
}

\begin{abstract}
Ameloblastoma is the most common epithelial odontogenic tumor. It may show locally invasive behavior resulting in recurrence and malignancy. Therefore, appropriate diagnosis of this tumor is necessary. The aim of this study was to evaluate clinicopathological characteristics of ameloblastomas in an Iranian population. We present a 40-year retrospective study of patients diagnosed from 1971 to 2010 in the Department of Oral and Maxillofacial Pathology, Faculty of Dentistry, Mashhad, Iran. Information gathered from patient records included age, gender, tumor location and histologic type. The frequency of odontogenic tumors among all lesions was $2.08 \%$ and ameloblastoma with 88 samples demonstrated the greatest prevalence $(\mathbf{4 1 . 5 \% )}$ ). Regarding gender, $60 \%$ of samples occurred in males. The mean age of studied patients was 33.02 \pm 15.74 years with a peak of occurrence in the third decade of life. The most frequent location of tumor was the mandibles $(93.2 \%)$. Eighty five (96.6\%) tumors were recorded as benign and $3(3.4 \%)$ as malignant. Of benign tumors, 62 (72.9\%), $20(23.5 \%)$ and $3(3.6 \%)$ cases were of conventional, unicyctic and peripheral types, respectively. In contrast to most previous studies, the most common histologic subtype in the present study was plexiform. Knowledge of the incidence of ameloblastoma and its clinicopathologic features including most common location, gender and age distribution in different ethnogeographic backgrounds is necessary for accurate diagnosis and proper treatment.
\end{abstract}

Keywords: Odontogenic tumor - ameloblastoma - plexiform

Asian Pac J Cancer Prev, 17 (2), 619-623

\section{Introduction}

Odontogenic tumors are lesions derived from epithelial or mesenchymal remnants. Therefore, these lesions are observed exclusively in the mandible and maxilla. Some of these lesions are real neoplasm which rarely represents behavior of malignant tumors; others may be considered as tumor-like malformation such as hamartoma (Manor et al., 1999; Kumamoto et al., 2000). By considering histological origin,odontogenic tumors are categorized in three groups: 1-Epithelial odontogenic tumors;odontogenic ectomesenchyme doesn't have role in their formation.2) Mixed odontogenic tumors; these tumors are composed of odontogenic epithelial and ectomesenchymal components. 3) Ectomesenchymal odontogenic tumors; basically formed from ectomesenchyme. Etiology and pathogenesis of related lesions are unclear and there is no evidence for specific cause or motive for them (Neville et al., 2009).

Ameloblastoma is the solid/multicystic odonyogeic tumor. It is the most common clinical tumor within all odontogenic tumors if odontoma is considered as hamartoma. According to the latest classification of World Health Organization (WHO), ameloblastoma is known as the prototype of odontogenic tumors with epithelial origin (Bachmann et al., 2005; Salehinejad et al., 2011). Improper diagnosis and treatment of this tumor may lead to significant morbidity and occasionally death. Its incidence in males and females is equal and the mean age of involvement is approximately 35 years. Ameloblastoma is divided into three types by considering clinical and radiography findings: conventional (86\%), unicystic (13\%) and peripheral (1\%) (Mendenhall et al., 2007).

Surgery is primary treatment but there has been still some debate for the most appropriate method of surgical removal .This debate ranges from conservative to radical modes of treatment (Vohra et al., 2007). The first step of treatment is an appropriate categorization of tumor and gaining knowledge about the incidence of histopathological subtypes as well as age, gender and involved site of lesion.

Due to the lack of information in the Englishlanguage literature about the clinicopathologic features of ameloblastoma in Iranian population, we reviewed ameloblastoma tumors over a 40 -year period. The purposes of this study were to evaluate the clinicopathologic features of ameloblastoma in Iranian population and to

${ }^{1}$ Oral and Maxillofacial Diseases Research Center, ${ }^{2}$ Dental Research Center, Department of Oral and Maxillofacial Pathology, School of Dentistry, Mashhad University of Medical Sciences, ${ }^{4}$ Private Office, Mashhad, Iran, ${ }^{3}$ Department of Prosthodontic, School of Dentistry, Vienna University of Medical Sciences, Vienna, Austria*For correspondence: Ghazin@mums.ac.ir 
Nasrollah Saghravanian et al

provide data for comparison with other Studies.

\section{Materials and Methods}

In this cross-sectional study we evaluated all files of the department of Oral and Maxillofacial Pathology, Faculty of Dentistry, Mashhad, Iran with diagnosis of odontogenic tumors from 1971 to 2010. All completed and detailed case files were entered the study and incomplete records were excluded from the study procedure.

Then histologic diagnosis records were reevaluated for patients who were treated for ameloblastoma. Then all types of Ameloblastoma were assessed based on histopathological findings and World Health Organization (WHO) classification.

When diagnosis was confirmed, information gathered about age, gender and location of tumor.

Recorded data were analyzed by SPSS version 11 , the descriptive data including demographics were expressed as Mean \pm SD (continuous quantitative variables). Frequency and percentiles were used for qualitative and discrete quantitative variables. And for comparing qualitative variables (gender, tumor type and position), the chi-square test was used. To analyze the age as a quantitative variable, the independent T-test was applied for dichotomous comparisons and Analysis of Variance (ANOVA) for more variables within more than two groups. In all calculations P-value less than 0.05 was considered significant.

To review the literature in term of published case series about Ameloblstoma, we searched Pubmed

Table 1. Frequency of Ameloblastoma Tumors among All Samples

\begin{tabular}{lccc}
\hline Decade & All samples & Ameloblastoma & Percentage \\
\hline $1971-1980$ & 1298 & 12 & 0.92 \\
$1981-1990$ & 2336 & 18 & 0.77 \\
$1991-2000$ & 3114 & 20 & 0.64 \\
$2001-2010$ & 3420 & 38 & 1.11 \\
\hline Total & 10168 & 88 & 0.86 \\
\hline
\end{tabular}

with the keywords with the following search strategy: (ameloblastoma AND jaws) AND ("retrospective studies" OR "retrospective analysis" OR "clinicopathological studies" OR "cases-analysis" OR "clinical review" OR "clinical features") we retrieved multiple papers then the data of relevant studies with retrospective descriptive design were extracted. By considering the archival mode of this study and using paraffin blocks, no ethical problem and privacy safety were assumed to be vital.

\section{Results}

We studied all case files of patients who referred to department of Oral and Maxillofacial Pathology, Faculty of Dentistry, Mashhad, Iran with diagnosis of odontogenic tumors during 1971 to 2010 . Of all odontogenic tumors $88(41.5 \%)$ were ameloblastoma (Table 1$)$.

Among them, 51(58\%) were recorded in men and $37(42 \%)$ in women. Chi-square test showed no significant difference for gender distribution in different decades $(\mathrm{P}=0.068)$.

Average age of studied individuals was $33.02 \pm 15.74$ years, (mean=33.02, SD 15.74). In terms of age groups, the highest percentage of patients was from 20-29 years category with 27 cases $(30.7 \%)$ followed by the age groups of 30-39 years and less than 20 years with $19(21.6 \%)$ and $17(19.3 \%)$ patients, respectively.

Regarding location of tumor, $82(93.2 \%)$ cases were in mandible, 3 cases in maxilla $(3.4 \%)$ and $3(3.4 \%)$ cases were located at soft tissue. From tumors which located in the mandible, $66(80.5 \%)$ cases were in posterior, 5 $(6.1 \%)$ cases were situated in the anterior of mandible and in $11(13.4 \%$ ) cases anteroposterior aspect was not recognizable (Table 2).

Among the maxillary tumors, there were two cases in the posterior region and one in the anterior region. One of the soft tissue tumors was in buccal mucosa and others were in mandibular posterior vestibule .

By considering the histological type of tumor, 85 $(96.6 \%)$ tumors were recorded as benign and $3(3.4 \%)$ as malignant. Among the benign tumors, 62 (72.9\%) cases

Table 2. Relative Frequency of Ameloblastoma

\begin{tabular}{|c|c|c|c|c|c|c|c|c|c|}
\hline \multirow[t]{4}{*}{$\mathrm{n}$} & \multirow[t]{4}{*}{ Mean age } & \multicolumn{2}{|c|}{ Gender } & \multirow{4}{*}{ Peripheral } & \multirow{2}{*}{\multicolumn{5}{|c|}{$\frac{\text { Location }}{\text { Central }}$}} \\
\hline & & \multirow[t]{3}{*}{ Male } & \multirow[t]{3}{*}{ Female } & & & & & & \\
\hline & & & & & \multicolumn{2}{|c|}{$\begin{array}{c}\text { Maxilla } \\
3\end{array}$} & \multicolumn{3}{|c|}{$\begin{array}{c}\text { Mandible } \\
82\end{array}$} \\
\hline & & & & & Ant. & Post. & Ant. & Post. & Unknown \\
\hline 88 & 33.02 & 51 & 37 & 3 & 1 & 2 & 5 & 66 & 11 \\
\hline
\end{tabular}

Table 3. Frequency of Different Clinical Subtypes of Ameloblastoma

\begin{tabular}{|c|c|c|c|c|c|c|c|}
\hline \multirow[t]{2}{*}{ Type of tumor } & \multirow[t]{2}{*}{$\mathrm{n}$} & \multicolumn{2}{|c|}{ Gender } & \multirow[t]{2}{*}{ Mean age } & \multicolumn{3}{|c|}{ Location of tumor } \\
\hline & & Male & Female & & $\begin{array}{c}85 \\
\text { Mandible }\end{array}$ & $\begin{array}{c}\text { Central } \\
3 \\
\text { Maxilla }\end{array}$ & Peripheral \\
\hline Conventional & 62 & 33 & 29 & 35.5 & 60 & 2 & 0 \\
\hline Unicystic & 20 & 13 & 7 & 24.5 & 19 & 1 & 0 \\
\hline Peripheral & 3 & 3 & 0 & 27.7 & 0 & 0 & 3 \\
\hline Carcinoma & 3 & 2 & 1 & 42.7 & 3 & 0 & 0 \\
\hline
\end{tabular}


were conventional, $20(23.5 \%)$ unicyctic and $3(3.6 \%)$ peripheral type (Table 3 ).

Our findings indicated that all peripheral ameloblastoma cases were observed within males and incidence of malignancy between males was two times more than females(Table 3). .Based on Likelihood Ratio test, there was no significant difference in distribution of tumor type according to gender $(\mathrm{P}=0.226)$. In spite of an increase in the number of ameloblastoma patients, the percentage of ameloblastoma cases among the whole samples showed a gradual decline between 1971 and 2000, and a gradual rise during 2000s in comparison to the previous decades.

Distribution of tumor types based on age range groups showed that among all types of benign tumors, the group of 20-29 years had the highest prevalence $(\mathrm{P}<0.05)$.

The comparison of mean age within different type of tumors showed that among benign tumors, the average age of those who had conventional type was higher than other groups. Also the average age of patients with peripheral tumors was more than patients with unicyctic tumors.

On the other hand, the average age of patients with malignant tumor was higher than benign group. Peripheral and malignant tumors were mostly seen in 20-29 and 4049 age groups respectively. According to the ANOVA test, the mean difference between these four mentioned groups was statistically significant $(\mathrm{P}=0.028)$.

Histopathologic findings showed that the plexiform ameloblastoma (26 cases, 46.4\%) was the most common type in both gender. According to Likelihood Ratio test, there was no significant difference between genders $(\mathrm{P}=0.524)$. Thereafter, follicular and follicular \& acantomathous had the most frequencies, 15 (26.8\%) and $4(7.1 \%)$ patients, respectively (Table4).

Table 4. Frequency of Conventional Tumors Based on Histopathologic Type

\begin{tabular}{lccc}
\hline Type of conventional tumors & $n$ & \multicolumn{2}{c}{ Gender } \\
& & Female & Male \\
\hline Plexiform & 26 & 10 & 16 \\
Follicular & 15 & 8 & 7 \\
Acanthomatous & 3 & 0 & 3 \\
Follicular \& acanthomatous & 4 & 2 & 2 \\
Plexiform \& basal cell & 3 & 1 & 2 \\
Desmoplastic & 2 & 1 & 1 \\
Follicular \& plexiform & 3 & 2 & 1 \\
Unknown type & 6 & - & - \\
\hline
\end{tabular}

In our findings, the most common site of tumors was the mandible except for peripheral tumor. A significant difference was observed between tumor types and its location, $(\mathrm{P}<0.001)$.

The findings (the most common histologic types, mean of age and male: female ratio) of 13 published studies reporting 1722 case of ameloblastoma are presented in Table 5.

\section{Discussion}

Ameloblastoma is the most important tumor among ectodermal odontogenic tumors. The relative incidence of this tumor is equal to incidence of all odontogenic tumors, except odontoma. Ameloblastoma wth invasive behavior and slow development rate is considered as the most common tumor between odontogenic tumors (Tamme et al., 2004).

In the current study, histological types of ameloblastoma are evaluated in an Iranian population for the first time.

Of 212 odontogenic tumors referred to Oral and Maxillofacial Pathology Department of Mashhad Dental School during forty years, 88 cases were ameloblastoma.

Saghravanian et al studied the dontogenic tumors in an Iranian population in a 30-year period. Correspondingly, they reported that the ameloblastoma was the most frequent tumor followed by odontoma, odontogenic myxoma, and adenomatoid odontogenic tumor (Saghravanian et al., 2010).

In consistent with our findings, several studies reported the ameloblastoma as the most common odontogenic tumor (Lu et al., 1998; Ladeinde et al., 2005; Simon et al., 2005; Jing et al., 2007; Avelar et al, 2011; Osterne et al., 2011). whereas some other studies demonstrated odontoma as the most frequent odontogenic tumor (Tawfik et al., 2010, Taklif et al., 2010) ; this difference could be due to the racial differences or sample size.

During forty years, the number of patients with ameloblastoma referred to our department was increased; this could be explained as an outcome of increasing the population of the country and worldwide. In terms of gender distribution, about $60 \%$ of cases were diagnosed in men. The findings indicated that in all over the study period, superiority of gender distribution was in males. Correspondingly, several studies showed that peripheral ameloblastoma cases were occurred among males (Razavi

Table 5. Compariative Incidence of Ameloblastoma in Different Published Studies

\begin{tabular}{|c|c|c|c|c|c|c|}
\hline Author & $\begin{array}{l}\text { Country } \\
\text { of study }\end{array}$ & $\begin{array}{l}\text { Total No. } \\
\text { of cases }\end{array}$ & $\begin{array}{l}\text { Most common } \\
\text { Histologic Type }\end{array}$ & $\begin{array}{c}\text { Mean of } \\
\text { Age }\end{array}$ & $\begin{array}{c}\text { Sex } \\
\text { predilection }\end{array}$ & $\begin{array}{l}\text { Most common } \\
\text { involved area }\end{array}$ \\
\hline Present study & Iran & 88 & Conventional & 3rd decade & Male & Mandible \\
\hline Chawla R et al. (2013) & India & 91 & plexiform and unicystic & 32.5 & Male & Mandible \\
\hline Butt F M et al. (2012) & Kenya & 127 & unknown & 2nd decade & Equal & Mandible \\
\hline Siar C H et al. (2012) & Malaysia & 340 & solid/multicystic & 2nd decade & Male & Mandible \\
\hline Ruhin-Poncet B et al. (2011) & France & 116 & Follicular & 36 & unknown & unknown \\
\hline DarshaniGunawardhanaks et al. (2010) & Sri Lanka & 286 & solid/multicystic & 33.2 & Equal & Mandible \\
\hline Fregnani E R et al. (2010) & Brazil & 121 & solid & 33.2 & Slight female predilection & Mandible \\
\hline Krishnapillai et al. (2010) & India & 73 & unicystic & 30.2 & Slight male predilection & Mandible \\
\hline Adeline V L et al. (2008) & Kenya & 184 & solid/multicystic & 30.2 & Female & Mandible \\
\hline Odukoya O (2008) & Nigeria & 100 & solid/multicystic & less than 20 years & Male & Mandible \\
\hline Adebiyi K E et al. (2006) & Nigeria & 77 & Follicular & 3rd decade & Male & Mandible \\
\hline Ladeinde AL et al. (2006) & Nigeria & 207 & Follicular & 31.67 & Male & Mandible \\
\hline
\end{tabular}


et al., 2001; Adebayo et al., 2005; Arotiba et al., 2005). Dhanuthai et al. showed that distribution of females was higher than males in their study (Dhanuthai et al., 2012). They found different results in comparison with ours, while Mosadomi et al observed that gender distribution was equal for males and females in Africa (Mosadomi, 1997).

In our study, ameloblastoma was observed in individuals with younger average age; but in Dhanuthai's study the mean age was 48 years that show older age than our samples (Dhanuthai et al., 2012).

The posterior region of the mandible is the most common location for ameloblastoma in the present study $(93.2 \%)$ followed by maxilla $(3.4 \%)$, which agrees with the studies performed in Asia, Europe, Africa and South America (Table 5) (Arotiba et al., 2005). According to the results of mentioned studies, it seems that odontogenic tumors particularly ameloblastoma more likely involve the lower face especially mandible (Fulco et al., 2010). Correspondingly, Kim et al. concluded that plexiform of conventional tumors possessed the most prevalence and the difference between two gender groups wasn't significant (Kim et al., 2001).

In the present study, the most common tumor was the conventional, whereas Ladeinde (Ladeinde et al., 2006) and Adebiyi (Adebiyi et al., 2006) from Nigeria and Ruhin-Poncet et al (Ruhin-Poncet et al., 2011) from France reported the follicular type as the most frequent; Odukoya (Odukoya et al., 2008) in Nigeria, Adeline (Adeline et al., 2008) in Kenya, Darshani et al (Darshani et al., 2010) in SriLanka (Siar et al 2012) in Malaysia declared the solid/ multi cystic as the most frequent tumor in their study. Chawla et al (2013) and Krishnapillai et al (Krishnapillai et al., 2010) in India reported the unicystic/plexiform and unicystic as the most common types, respectively. Fregnani et al (Fregnan et al., 2010) showed the solid one was the most frequent in Brazil, while Butt et al (2012) in Kenya couldn't report the most abundant tumor .

In conclusion, according to our findings, ameloblastoma is the most common odontogenic tumor in the mandible and in males with most cases appearing in the third decade of life. Most of the ameloblastic tumors are benign and the conventional type is the most reported one.Our findings confirm worldwide studies results although there are some differences, especially in histological subtypes.

\section{Acknowledgements}

This study was supported by a grant from the Vice Chancellor of Mashhad University of Medical Sciences, Iran.

\section{References}

Adebayo E, Ajike S, Adekeye E (2005). A review of 318 odontogenic tumors in Kaduna, Nigeria. J Oral Maxillofac Surg, 63, 811-9.

Adebiyi KE, Ugboko VI, Omoniyi-Esan GO, (2006). Clinicopathological analysis of histological variants of ameloblastoma in a suburban Nigerian population. Head Face Med, 2, 42 .
Adeline VL, Dimba EA, Wakoli KA, et al (2008). Clinicopathologic features of ameloblastoma in Kenya: a 10-year audit. J Craniofac Surg, 19, 1589-93.

Arotiba GT,Ladeinde AL, Arotiba JT, et al (2005). Ameloblastoma in Nigerian children and adolescents: a review of 79 cases. J Oral Maxillofac Surg, 63, 746-51.

Avelar RL, Primo BT, Pinheiro-Nogueira CB, et al (2011). Worldwide incidence of odontogenic tumors. $J$ Craniofacl Surg, 22, 2118-23.

Bachmann AM, Linfesty RL(2009). Ameloblastoma, solid/ multicystic type. Head Neck Pathol, 3, 307-9.

Butt FM, Guthua SW, Awange DA, et al (2012). The pattern and occurrence of ameloblastoma in adolescents treated at a university teaching hospital, in Kenya: a 13-year study. $J$ Cranio-Maxillo-Fac Surg, 40, 39-45.

Chawla R, Ramalingam K, Sarkar A, et al (2013). Ninetyone cases of ameloblastoma in an Indian population: A comprehensive review. J Nat Sci Biol Med, 4, 310-5.

Darshani Gunawardhana KS, Jayasooriya PR, Rambukewela IK, et al (2010).Clinico-pathological comparison between mandibular and maxillary ameloblastomas in Sri Lanka. $J$ Oral Pathol Med, 39, 236-41.

Dhanuthai K, Chantarangsu S, Rojanawatsirivej S, et al (2012). Ameloblastoma: a multicentric study. Oral Surg Oral Med Oral Pathol Oral Radiol, 113, 782-8.

Fregnan E, da Cruz Perez DE, de Almeida OP, et al (2010). Clinicopathological study and treatment outcomes of 121 cases of ameloblastomas. Int J Oral Maxillofac Surg, 39, 145.

Fulco GM, Nonaka CF, Souza LB, et al (2010).Solid ameloblastomas - Retrospective clinical and histopathologic study of 54 cases. Braz J Otorhinolaryngol, 76, 172-7.

Jing W, Xuan M, Lin Y, et al (2007). Odontogenic tumours: a retrospective study of 1642 cases in a Chinese population. Int J Oral Maxillofac Surg, 36, 20-5.

Kim SG, Jang H S(2001). Ameloblastoma: a clinical, radiographic, and histopathologic analysis of 71 cases. Oral Surg Oral Med Oral Patho Oral Radiol Endod, 91, 649-53.

Krishnapillai R, Angadi PV (2010). A clinical, radiographic, and histologic review of 73 cases of ameloblastoma in an Indian population. Quint Int, 41, 90-100.

Kumamoto H, Yamazaki S, Sato A, et al (2000). Clear cell odontogenic tumor in the mandible: report of a case with duct-like appearances and dentinoid induction. J Oral Pathol Med, 29, 43-7.

Ladeinde AL, Ajayi OF, Ogunlewe MO, et al (2005). A. Odontogenic tumors: a review of 319 cases in a Nigerian teaching hospital. Oral Surg Oral Med Oral Pathol Oral Radiol Endod, 99, 191-5.

Ladeinde AL, Ogunlewe M O, Bamgbose BO, et al (2006). Ameloblastoma: analysis of 207 cases in a Nigerian teaching hospital. Quint Int, 37, 69-74.

Lu Y, Xuan M, Takata T, et al (1998). Odontogenic tumors. A demographic study of 759 cases in a Chinese population. Oral Surg Oral Med Oral Pathol Oral Radiol Endod, 86, 707-14.

Manor Y, Merdinger O, Katz J, et al (1999). Unusual peripheral odontogenic tumors in the differential diagnosis of gingival swellings. J Clin Periodontol, 26, 806-9.

Mendenhall WM, Werning JW, Fernandes R, et al (2007). Ameloblastoma. Am J Clin Oncol, 30, 645-8.

Mosadomi A(1975). Odontogenic tumors in an African population. Analysis of twenty-nine cases seen over a 5-year period. Oral Surg Oral Med Oral Pathol, 40, 502-21.

Neville BW, Damm DD, Allen CM BJ (2009). Oral \& maxillofacial pathology, 3rd ed, Saunders, 702-11.

Odukoya O, Effiom OA (2008). Clinicopathological study of 
100 Nigerian cases of ameloblastoma. Niger Postgrad Med $J, 15,1-5$.

Osterne RL, Brito RG, Alves AP, et al (2011). Odontogenic tumors: a 5-year retrospective study in a Brazilian population and analysis of 3406 cases reported in the literature. Oral Surg Oral Med Oral Pathol Oral Radiol Endod, 111,474-81.

Razavi SM., Khazaeli A (2001). Ameloblastoma and its prevalence among patients referred to five major Iranian Dental Schools in a period of ten years (1988-1998). Shaheed Beheshti Univ Dent J, 19, 9-15.

Ruhin-Poncet B, Bouattour A, Picard A, et al (2011). Ameloblastoma of the jaws. A retrospective analysis from 1994 to 2007. Rev Stomatol Chir Maxillofac, 11, 269-79.

Saghravanian N, Jafarzadeh H, Bashardoost N, et al (2010). Odontogenic tumors in an Iranian population: a 30-year evaluation. J Oral Sci, 52, 391-6.

Salehinejad J, Zare-Mahmoodabadi R, Saghafi S, et al (2011). Immunohistochemical detection of p53 and PCNA in ameloblastoma and adenomatoid odontogenic tumor. J Oral Sci, 53, 213-7.

Siar CH, Lau SH, Ng KH (2012). Ameloblastoma of the jaws: a retrospective analysis of 340 cases in a Malaysian population. J Oral Maxillofac Surg, 70, 608-15.

Simon EN, Merkx MA, Vuhahula E, et al (2005). A 4-year prospective study on epidemiology and clinicopathological presentation of odontogenic tumors in Tanzania. Oral Surg Oral Med Oral Pathol Oral Radiol Endod, 99, 598-602.

Taklif M, Samiee Rad F(2010). Prevalence of jaw cysts (odontogenic cysts, tumors \& mesenchymal lesions) and correlation of clinicoradiopathologic features of them. Razi J Med Sci, 13, 75-81.

Tamme T, Soots M, Kulla A, et al (2004). Odontogenic tumours, a collaborative retrospective study of 75 cases covering more than 25 years from Estonia. J Craniomaxillofac Surg, 32, 161-5.

Tawfik MA, Zyada MM (2010). Odontogenic tumors in Dakahlia, Egypt: analysis of 82 cases. Oral Surg Oral Med Oral Pathol Oral Radiol Endod, 109, 67-73.

Vohra F, Hussain M, Mudassir M (2009). Ameloblastomas and their Management: A review. J Surg Pak, 1, 55. 